\title{
Age at immigration to England of Asian and Caribbean immigrants and the risk of developing multiple sclerosis
}

\author{
Geoffrey Dean, Marta Elian
}

\begin{abstract}
Objectives-Previous studies have shown that multiple sclerosis is very uncommon among Indian and Pakistani immigrants to England but that their children born in the United Kingdom, in the age groups available for study, have a similar risk of developing the disease as occurs in the general British population. The present study was to ascertain if these immigrants who enter England as children below the age of 15, have a higher risk of developing multiple sclerosis than those that enter after this age.

Methods-A search was made in Greater London, the West Midlands, Leicester, Bradford, Halifax, and Huddersfield to find ethnic Indian, Pakistani, and Bangladeshi immigrants to England with multiple sclerosis. During the course of the study some immigrants from the Caribbean with multiple sclerosis were also found. The population at risk by ethnic group and age at entry was not available from the 1991 Census but was available in the annual Labour Force Surveys.

Results-Indian and Pakistani immigrants who entered England younger than 15 had a higher risk of developing multiple sclerosis than those that entered after this age. Caribbean immigrants, who have a higher multiple sclerosis prevalence than Asian immigrants, did not show this difference.

Conclusion-This study confirms previous studies which show that the environment during childhood is a major factor in determining the risk of developing multiple sclerosis.
\end{abstract}

(F Neurol Neurosurg Psychiatry 1997;63:565-568)

The Medico-Social

Research Board

Dublin, Ireland

G Dean

Department of Neurology, Central Middlesex Hospital, London, England M Elian

Correspondence to: Dr Geoffrey Dean, PO Box 1851, Ballsbridge, Dublin 4, Ireland.

Received 25 July 1996 and in revised form 18 December 1996

Accepted 27 March 1997 who had migrated to England, as has been reported among those who did not migrate..$^{7-9}$ Multiple sclerosis was relatively uncommon among West Indian immigrants but not as uncommon as it was among ethnic Asian immigrants. Children of Asian and West Indian immigrants born in England and Wales, in the age group available for study, had a similar prevalence of multiple sclerosis to that in the general population of England and Wales. ${ }^{10}{ }^{11}$ Although the number of Asian immigrants with multiple sclerosis from the Indian subcontinent and from East Africa is still small, it is now large enough to ascertain whether these immigrants have a higher risk of developing multiple sclerosis if they migrate to England as children.

\section{Method}

The search for Indian, Pakistani, and Bangladeshi patients with multiple sclerosis has been continued since 1972. It has included hospitals in Greater London and the West Midlands and also Leicester, Bradford, Halifax, and Huddersfield; $70 \%$ of the ethnic Indian and Bangladeshi, $57 \%$ of the Pakistani, and $65 \%$ of the West Indians in England live in the areas studied. ${ }^{12}$

The diagnostic indices in the hospitals in the areas under study continued to be searched for patients with multiple sclerosis who had Indian, Muslim, African, or Chinese names or belonged to other than Judeo-Christian religions. Their hospital records were then studied. Other sources were used to identify Asian and Caribbean born patients with multiple sclerosis - that is, repeated enquiries from neurologists, their secretaries, registrars, and general practitioners. As a result, a further group of Caribbean born patients with multiple sclerosis was also found. No attempt was made to trace all the Caribbean patients with multiple sclerosis in the areas studied. Because Caribbean immigrants generally have British or Irish names, their identification as West Indians is more difficult. Previous studies have shown that Caribbean immigrants to England have a higher prevalence of multiple sclerosis than Asian immigrants. ${ }^{78}$

The diagnosis of multiple sclerosis, classified according to the Poser classification, ${ }^{13}$ was confirmed from the information obtained from the case notes.

The age at immigration to England was obtained from the patient's case notes or from the patient's general practitioner. The NHS 
Table 1 Labour force survey 1992 age at immigration of immigrants to England excluding those aged under 15 in 1992

\begin{tabular}{|c|c|c|c|c|c|c|c|}
\hline \multirow[b]{2}{*}{ Ethnic group } & \multicolumn{2}{|l|}{ Male } & \multicolumn{2}{|l|}{ Female } & \multicolumn{3}{|c|}{ Both sexes } \\
\hline & Total & $\begin{array}{l}\text { Entered } \\
\text { Under } 15\end{array}$ & Total & $\begin{array}{l}\text { Entered } \\
\text { Under } 15\end{array}$ & Total & $\begin{array}{l}\text { Entered } \\
\text { Under } 15\end{array}$ & $\%$ \\
\hline Indian & 270790 & 78887 & 274903 & 72248 & 545693 & 151135 & 27.7 \\
\hline Pakistani & 125645 & 41673 & 116874 & 22065 & 242519 & 63738 & 26.3 \\
\hline Bangladeshi & 49599 & 20354 & 42766 & 7836 & 92365 & 28190 & 30.5 \\
\hline Black Caribbean & 94807 & 26335 & 107957 & 31012 & 202764 & 57347 & 28.3 \\
\hline
\end{tabular}

Central Register, Southport, also helped us obtain some of this information. Six Indian or Pakistani immigrants with definite multiple sclerosis were excluded from the study because they had their first symptoms before arriving in the United Kingdom. There was also one black patient with multiple sclerosis, born in Trinidad, who was excluded because both of his parents were born in West Africa.

The denominator in this study presented a special difficulty because the 1991 Population Census did not provide a breakdown of the immigrants by ethnic group nor by age at immigration of each ethnic group. This information was available only from a special analysis undertaken by the Labour Force Surveys. We were provided with a breakdown from these Surveys by ethnic group by age in five-year age groups and by sex and also by age at entry for 1986, 1987, and $1988^{14}$ and, recently, for $1992 .{ }^{15}$ The sample size of the Labour Surveys was small $(1 \%)$. However, the proportion in the different sex and ethnic groups who had entered the country below the age of 15 was similar in all four Labour Force Surveys. Table 1 shows the calculated populations at risk from the 1992 survey; 1 January 1990 was designated prevalence day. The actual and expected age at entry in each sex and age group was then calculated.

\section{Results}

Seventy six ethnic Indian, Pakistani, or Bangladeshi immigrants, alive on prevalence day, had definite or probable multiple sclerosis (table 2). Fifty eight of the 76 patients who had developed their first symptoms of multiple sclerosis in England were Indian, (23 male, 35 female). Seventeen were Pakistani, (eight male, nine female), and one was Bangladeshi (female). Twenty three of the Indian patients with multiple sclerosis (four male, 19 female) were born in the Indian subcontinent, 31 in the new Commonwealth countries of East Africa-that is, Kenya, Uganda, Tanzania, Zambia, and Malawi (16 male, 15 female) - and one female and three male Indian patients with multiple sclerosis were born elsewhere; two in Fiji, one in Malaya, and one in Sri Lanka. Fifteen of the 17 Pakistani patients were born in Pakistan or in the Indian subcontinent (seven male, eight female) and two were born in East Africa (one male, one female). The Bangladeshi was born in Bangladesh.

Table 2 shows the actual and expected number of patients with multiple sclerosis by age at immigration and by sex. A larger number of ethnic Indian patients with multiple sclerosis, 26, had migrated to England under the age of 15 , than the calculated expected number (15.5, $\left.\chi^{2}=7.1, \mathrm{P}<0.01\right)$. The number of Pakistani patients with multiple sclerosis under the age of 15 years, 10, was also greater than the calculated expected number $\left(4.3, \chi^{2}=7.6\right.$, $\mathrm{P}<0.01$ ). If the one Bangladeshi patient is included and the Pakistani and Bangladeshi populations in the different age groups are taken together, the expected number is $4.9\left(\chi^{2}\right.$ $=5.3, \mathrm{P}<0.05)$. The number of patients with multiple sclerosis in each of the five-year age groups; 0-4, 5-9, 10-14, was also greater than the expected number.

For the Indian and Pakistani immigrants considered together, there were 36 patients with multiple sclerosis who immigrated below the age of 15 and the expected number is 19.8 $\left(\chi^{2}=13.3, \mathrm{P}<0.001\right)$. Among males there were 15 younger than 15 and 9.4 expected, $\left(\chi^{2}=\right.$ 3.3), just below significance at the $5 \%$ level. There were 21 female patients with multiple sclerosis who had immigrated under 15 years of age and 10.4 expected $\left(\chi^{2}=10.8, P<0.001\right)$, a highly significant difference.

One Indian patient was very unusual. She came to England when she was 2 years old. At the age of 4 she developed failure of vision, first in the left eye and then in the right eye. Her vision recovered in six weeks. At the age of seven she developed an attack of dysphagia and dysarthria. Brain CT showed enhancing low attenuation lesions in the brain. After 10 weeks these symptoms disappeared. At the age of 8

Table 2 Multiple sclerosis among Indian and Pakistani immigrants to England and Wales by age at immigration

\begin{tabular}{|c|c|c|c|c|c|c|c|c|c|c|c|c|c|c|c|c|c|c|}
\hline \multirow{3}{*}{$\begin{array}{l}\text { Age } \\
\text { group }\end{array}$} & \multicolumn{6}{|c|}{ Indian immigrants } & \multicolumn{6}{|c|}{ Pakistani immigrants } & \multicolumn{6}{|c|}{ Indian and Pakistani immigrants } \\
\hline & \multicolumn{3}{|c|}{ Actual MS } & \multicolumn{3}{|c|}{ Expected No } & \multicolumn{3}{|c|}{ Actual MS } & \multicolumn{3}{|c|}{ Expected No } & \multicolumn{3}{|c|}{ Actual MS } & \multicolumn{3}{|c|}{ Expected No } \\
\hline & $M$ & $F$ & Total & $M$ & $F$ & Total & $M$ & $F$ & Total & $M$ & $F$ & Total & $M$ & $F$ & Total & $M$ & $F$ & Total \\
\hline $0-4$ & 1 & 6 & 7 & 2.1 & 2.8 & 4.9 & 1 & 4 & 5 & 1.2 & 0.9 & 2.1 & 2 & 10 & 12 & 3.3 & 3.7 & 7.0 \\
\hline $5-9$ & 3 & 5 & 8 & 2.1 & 2.5 & 4.6 & 2 & - & 2 & 0.8 & 0.6 & 1.4 & 5 & 5 & 10 & 2.9 & 3.1 & 6.0 \\
\hline $10-14$ & 7 & 4 & 11 & 2.5 & 3.5 & 6.0 & 1 & 2 & 3 & 0.7 & 0.1 & 0.8 & 8 & 6 & 14 & 3.2 & 3.6 & 6.8 \\
\hline $15-19$ & 6 & 3 & 9 & 4.1 & 6.9 & 11.0 & 1 & - & 1 & 1.3 & 2.2 & 3.5 & 7 & 3 & 10 & 5.4 & 9.1 & 14.5 \\
\hline $20-29$ & 5 & 11 & 16 & 7.6 & 12.0 & 19.6 & 2 & 2 & 4 & 2.7 & 3.3 & 6.0 & 7 & 13 & 20 & 10.3 & 15.3 & 25.6 \\
\hline $30+$ & 1 & 6 & 7 & 4.7 & 7.2 & 11.8 & 1 & 1 & 2 & 1.3 & 1.8 & 3.1 & 2 & 7 & 9 & 6.0 & 9.0 & 15.0 \\
\hline Total & 23 & 35 & 58 & 23.1 & 34.9 & 57.9 & 8 & 9 & 17 & 8.0 & 8.9 & 16.9 & 31 & 44 & 75 & 31.1 & 43.8 & 74.9 \\
\hline
\end{tabular}

Note: There was also one Bangladeshi female immigrant who entered England aged 28. 
she developed weakness and numbness in the right leg with great difficulty in walking. The left planter response was extensor. She recovered spontaneously in about six weeks. When she was 12 she had a recurrence of blurring of vision in the right eye followed a week later by severe blurring of vision in the left eye; bilateral central scotoma and optic atrophy was found. Because of her repeated attacks, multiple sclerosis was the probable diagnosis. On prevalence day she was 20 years of age.

Only one patient with multiple sclerosis stated that she was from Bangladesh. She entered England when she was 28. If the Bangladeshi immigrant population had the same risk of developing multiple sclerosis as had occurred among the Pakistani immigrants, the calculated expected number of Bangladeshi patients with multiple sclerosis would be 6 (6.2). Bangladesh was the Bengali province of western Pakistan before 1971, but none of the Pakistani patients with multiple sclerosis were from the area now Bangladesh. Seventy six per cent of the Bangladeshi live in London; $63 \%$ in Inner London, ${ }^{12}$ an area where there was a concentrated search for Asian immigrants.

The mean age at diagnosis of multiple sclerosis among the Indian immigrant population was 29.4 (male 27.9; female 30.4) years and for the Pakistani immigrant population 28.2 (male 28.7; female 27.6) years. For the Indian and Pakistani immigrants together the mean age at diagnosis was 29.1 (male 28.1, female 29.9) years. The mean age of the Indian immigrant patients with multiple sclerosis, male and female, on prevalence day was 38.2 and for the Pakistani patients 40.6 (male 47.6; female 32.8) and, for the Indian and Pakistani patients with multiple sclerosis taken together, the mean age was 38.7 (male 40.8; female 37.2). There was, therefore, a difference of 9.6 years between the mean age at diagnosis, 29.1, and the mean age on prevalence day, 38.7. It is difficult from the patient's records to be sure about the time of the first symptom or symptoms because very often the first symptom may not be recorded. The mean period between the first recorded symptom on the patient's hospital record and a definite diagnosis of multiple sclerosis was 2.1 years. There was therefore a mean period of 11.7 years from the first recorded symptom of multiple sclerosis to prevalence day.

The mean age of the first recorded symptom of multiple sclerosis on the medical records among the immigrants, Indian and Pakistani, who entered England below the age of 10 was lower than among those who arrived after this age. For those who immigrated below the age of five, the mean age of their first recorded symptom, excluding the one unusual patient described above whose first symptom was at four years of age, was 17.6 years. For those who immigrated aged 5-9 it was also low, 17.9 years. For those who immigrated aged 10-14 the mean age of recorded first symptom was similar to that among those who immigrated as adults, 26.8 years.

Five Parsi patients with multiple sclerosis, (one male, four female), all born in India, three in Bombay, were found during the course of the study out of a total Parsi population, mostly immigrants, in England and Wales of 5000 (estimate of Zoroastrian and Iranian Associations, London). ${ }^{16}$ The high prevalence of multiple sclerosis in Parsis is confirmed by the high prevalence found among the Parsis in Bombay by contrast with the low prevalence in the ethnic Indian population. ${ }^{17}$

Sixty patients with multiple sclerosis born in the Caribbean were found alive on prevalence day ( 15 male, 45 female). Of these 17 (four male, 13 female) had migrated to England before the age of 15 and the calculated expected number was also 17. Age at immigration had not, therefore, had any effect on the risk of developing multiple sclerosis among this random sample of Caribbean born patients with multiple sclerosis. Thirty one of these patients came from Jamaica, the remainder from other countries in the Caribbean and from British Guyana.

Three male ethnic black patients were found; one from Trinidad, one from Nigeria, and one from Ghana and two half white and half Ghanaian patients, both born in Ghana. There were 153000 black African immigrants, most of whom came from West Africa. This confirms that multiple sclerosis is very uncommon among ethnic Africans. ${ }^{18}$ Only two Chinese patients with multiple sclerosis were found out of a total of 45000 Chinese immigrants, evidence that multiple sclerosis is uncommon among the Chinese immigrants, as it is in China. ${ }^{19}$

\section{Discussion}

Twin studies suggest that genetic factors play an important part in predisposing to multiple sclerosis. ${ }^{20}$ There is a low prevalence of multiple sclerosis in both first and second generation Chinese and Japanese in Hawaii compared with the white population, again evidence for a genetic factor. ${ }^{21}$ Multiple sclerosis is uncommon in Malta in comparison with nearby Sicily ${ }^{22-26}$ and whether this is due to genetic or environmental factors is not yet known.

That an environmental factor must also play an important part is seen from epidemiological studies. ${ }^{4-6}$ Multiple sclerosis has a high prevalence where there is a high standard of living and Poskanzer et al were the first to suggest that multiple sclerosis may be due to the age at which various virus infections occur and that when they occur at a young age lifelong immunity is conferred, ${ }^{27}$ as occurred with poliomyelitis among the white South African born population. ${ }^{28}$

The highest multiple sclerosis mortality in women in England and Wales was in social class I, the professional class (SMR 131), based on the 1971 and on the 1981 censuses. In men, the highest multiple sclerosis mortality was in social class IIIN skilled non-manual labourers (SMR 150). This may represent a fall in socioeconomic status due to the progress of the disease, whereas married women maintain the social class of their husband. The second highest mortality in men was in social class I 
(SMR 119). ${ }^{29}$ At the onset of multiple sclerosis, rather than at death, men in social class 1 have the highest risk of developing the disease. ${ }^{30} \mathrm{In}$ the present study no comparison has been made of the socioeconomic grouping of the patients with multiple sclerosis with that of the general Indian or Pakistani population but, particularly among the Indian and Parsi patients with multiple sclerosis, a higher than expected number were of upper socioeconomic group. Four were doctors; three Indian and one Parsi, and two were doctors' wives. A further study is now under way to compare the social class of the Asian patients with multiple sclerosis with a control population.

We considered including motor neuron disease as a control disorder as had been done with multiple sclerosis and motor neuron disease mortality. ${ }^{8}$ This was not practical at present because the prevalence of motor neuron disease in the young Asian population is low. A previous study also showed that Asian immigrants had a lower mortality from motor neuron disease, age standardised, than occurred at English rates. ${ }^{8}$

The present report, which shows that Indian and Pakistani immigrants to England who come as children, below the age of 15 , have a significantly higher risk of developing multiple sclerosis than those that enter the country after this age, is the reverse of the South African and Israeli findings and is additional evidence for the importance of environmental factors in childhood in causing multiple sclerosis. That only one Bangladeshi was found when six was the expected number at Pakistani immigrant rates, may be because the Bangladeshi immigrants have a lower prevalence of multiple sclerosis than the Pakistani immigrants or it may be due to chance.

The early onset of multiple sclerosis in the Asian immigrants who entered England below the age of 10 is striking; the reason for this is not known but could be due to early exposure to the environmental factors predisposing to multiple sclerosis in northern Europe.

A young age at immigration seems to play a considerably more important part in Asian women compared with Asian men and apparently plays no part at all in black women or black men. The "environmental shock"- that is, the difference in the environment before and after immigration-is perhaps more pronounced among Asian women.

We do not know why West Indian immigrants that enter England as children do not seem to have a higher risk of developing multiple sclerosis than those that come as adults. Possible reasons may be that the West Indian immigrants already have a considerably higher prevalence of multiple sclerosis than Asian immigrants so any effect of age at immigration would be lessened and because the effect of age at immigration that we have found among the Asian immigrants is small.

We thank the many people who have assisted us with this study, including the neurologists, medical registrars, medical officers, and the staff of the Medical Records departments of the hospi- tals that took part in the study. Mr Ian Thurman, of the Office of Population Censuses and Surveys London, and Ms Julia Moore, of Quantime, advised us and provided us with information from the Censuses and the Labour Force surveys. Ms Hilda McLaughlin and Ms Maureen Moloney provided statistical and secretarial assistance. The study was supported by a grant from the Multiple Sclerosis Society of Great Britain and Northern Ireland.

1 Matthew WB, Compston A, Allen IV, Martyn CN, eds. Mcalpine's multiple sclerosis. 2nd ed. Edinburgh: Churchill Livingstone, 1990.

2 Dean G. Disseminated sclerosis in South Africa. BMF 1949; i: $842-3$.

3 Dean G. Annual incidence, prevalence and mortality of multiple sclerosis in white South African-born and in white immigrants to South Africa. BMF 1967;ii:724-30.

4 Dean G, Kurtzke J. On the risk of multiple sclerosis according to age at immigration to South Africa. BMF 1971;ii:725-9.

5 Kurtzke JF, Dean G, Botha DPJ. A method for estimating the age at immigration of white immigrants to South Africa, with an example of its importance. $S$ Afr Med $\mathcal{F}$ 1970;44:663-9.

6 Alter M, Leibowitz U, Speer J. Risk of multiple sclerosis related to age at immigration to Israel. Arch Neurol 1966;15:234-7.

7 Dean G, McLoughlin H, Brady R, Adelstein AM, Tallett-Williams J. Multiple sclerosis among immigrants in Greater London. BMf 1976;1:861-4.

8 Dean G, Brady R, McLoughlin H, Elian M, Adelstein AM. Motor neurone disease and multiple sclerosis among immigrants to Britain. Br f Prev Soc Med 1977;31:141-7.

9 Jain S, Maheshwari MC. Multiple sclerosis: Indian experience in the last 30 years. Neuroepidemiology 1985;4: 96-107.

10 Elian M, Nightingale S, Dean G. Multiple sclerosis among United Kingdom-born children of immigrants from the Indian subcontinent, Africa, and the West Indies. F Neurol Neurosurg Psychiatry 1990;53:906-11.

11 Elian M, Dean G. Motor neuron disease and multiple sclerosis among immigrants to England from the Indian subcontinent, the Caribbean and East and West Africa. $f$ Neurol Neurosurg Psychiatry 1993;56:454-7.

12 Great Britain Monitor. 1991 Census. London: Office of Population Censuses and Surveys, 1991

13 Poser CM, Paty DW, Scheinberg L, et al. New diagnostic criteria for MS guidelines for research protocols. Ann Neurol 1983;13:227-31.

14 Labour Force Survey 1986, 1987, 1988. London: Office of Populations, Censuses and Surveys, 1988.

15 Labour Force Survey 1992. London: Office of Populations, Censuses and Surveys and Quantime, 1992.

16 Dean G, Wadia NH. Multiple sclerosis in the Parsis. 7 Neurol Neurosurg Psychiatry 1995;58:254.

17 Bharucha NE, Bharucha EP, Wadia NH, Singhal BS, Bharucha AK, Bhise AV, et al. Prevalence of multiple sclerosis in the Parsis of Bombay. Neurology 1988;38:727-9.

18 Dean G, Bhigjee AIG, Bill PLA, Fritz V, Chikanza IC, Thomas JEP, Levy LF. Multiple sclerosis in black South Africans and Zimbabweans. I Neurol Neurosurg Psychiatry 1994;57:1064-9.

19 Arnason BGW, Davis FA, Dean G, Kelly R, Sever JL, Waksman BH. China demyelinating diseases. Lancet 1982;ii: 734 .

20 Sadovnik AD, Armstrong H, Rice GPA, Bulman D, Hashimoto L, Paty DW, et al. A population-based twin study of multiple sclerosis. Ann Neurol 1993;33:281-5.

21 Alter M, Okihiro M, Rowley R, Morris T. Multiple sclerosis among Orientals and Caucasians in Hawaii. Neurology 1971;21:122-30

22 Dean G, Grimaldi G, Kelly R, Karhausen L. Multiple sclerosis in southern Europe. I: prevalence in Sicily in 1975. $\mathcal{F}$ Epidemiol Community Health 1979;33:111-3.

23 Dean G, Savettieri G, Giordano D, Butera C, Taibi G, Morreale $S$, Karhausen $\mathrm{L}$. The prevalence of multiple sclerosis in Sicily. Il: Agrigento City. 7 Epidemiol Community Health 1981;35:118-22.

24 Savettieri G, Daricello B, Giordano D, Karhausen L, Dean $\mathrm{G}$. The prevalence of multiple sclerosis in Sicily. I: Monreale City. F Epidemiol Community Health 1981;35:2:114-7.

25 Savettieri G, Elian M, Giordano D, Grimaldi G, Ventura A, Dean G. A further study on the prevalence of multiple sclerosis in Sicily. Caltanissetta city. Acta Neurol Scand 1986;73:71-5.

26 Vassallo L, Elian M, Dean G. Multiple sclerosis in southern Europe. Il: prevalence in Malta in 1978. F Epidemiol Community Health 1979;33:111-3.

27 Poskanzer DC, Shapira K, Miller H. Multiple sclerosis and poliomyelitis. Lancet 1963;ii:917-21

28 Dean G. Poliomyelitis among white immigrants to South Africa. S Afr Med f 1967;41:294-7.

29 Elian M, Dean G. The changing mortality from motor neuron disease and multiple sclerosis in England and Wales and the Republic of Ireland. Neuroepidemiology 1992;11: 236-43.

30 Russel WR. Multiple sclerosis: occupation and social group at onset. Lancet 1971;ii:832-4. 